\title{
ÁREAS URBANAS DE GÉNESE ILEGAL — PROBLEMAS \\ SUSCITADOS POR UM REGIME LEGAL EXCEPCIONAL \\ QUE TEIMA EM PERPETUAR-SE NO TEMPO
}

\author{
A propósito do Ac. Rel. Lisboa, de 8-02-2018, \\ P. ${ }^{\circ} 15101 / 15.2$ T8LRS-A-2*
}

\section{Dulce Lopes**}

\begin{abstract}
SUMÁrIO: 1. Notas Introdutórias; 2. Caraterísticas das AUGI e do seu processo de reconversão; 3. Regime jurídico das ARU; 4. AUGI e ARU: cruzamentos no caso vertente; 5. Repartição de responsabilidades e encargos; 6. Notas conclusivas
\end{abstract}

RESUmo: O presente comentário analisa a intersecção entre regimes jurídicos das áreas urbanas de génese ilegal e das áreas de reabilitação urbana, visando a clarificação das responsabilidades administrativas e financeiras em cada um deles, tendo por mote o caso concreto apreciado pelo Tribunal da Relação de Lisboa.

Palavras-Chave: Áreas Urbanas de Génese Ilegal; Áreas de Reabilitação Urbana; Administração Conjunta; Comparticipações; Competências e Responsabilidades.

ABstraCt: The present commentary analysis the intersection between the legal frameworks of illegal urban areas and urban rehabilitation areas. It aims to clarify both the administrative and financial responsibilities in each of those regimes, taking into consideration the case decided by the Lisbon Court of Appeals.

KeYwORDs: Illegal Urban Areas; Urban Rehabilitation Areas; Joint Administration; Co-Payments; Competences and Responsibilities.

\footnotetext{
* E, indirectamente, o Ac. Rel., Lisboa, de 18-02-2020, P. o 6245/18.0T8LRS.L1 que julgou improcedente a apelação, mantendo a decisão recorrida. Dada a extensão destes Acórdãos, remete-se para os respectivos textos disponíveis em www.dgsi.pt.

** Professora Auxiliar da Faculdade de Direito da Universidade de Coimbra, Investigadora e Membro do Conselho Coordenador do Instituto Jurídico da Universidade de Coimbra.
} 


\section{NOTAS INTRODUTÓRIAS}

O presente comentário chama a atenção para algumas das questões que têm sido suscitadas pelo regime jurídico das áreas urbanas de génese ilegal (AUGI), aprovado pela Lei n. ${ }^{\circ}$ 91/95, de 2 de Setembro, regime jurídico expressamente qualificado pelo legislador como excepcional mas que, na realidade, se tem vindo a perpetuar no tempo ${ }^{1}$. Se compararmos o seu âmbito territorial de aplicação inicial (prazo de vigência) segundo o qual cessaria a aplicação da presente lei às AUGI que não disponham de título de reconversão até 31 de Dezembro de 1999 (artigo 57. ${ }^{\circ}$ ), com a atual formulação desta disposição, que admite que "para efeitos de aplicação da presente lei, devem as AUGI dispor de comissão de administração validamente constituída até 31 de dezembro de 2016 e de título de reconversão até 30 de junho de 2021" (n. ${ }^{\circ} 1$ ) e que "a câmara municipal pode delimitar as AUGI, fixando como respectiva modalidade de reconversão a iniciativa municipal sem o apoio da administração conjunta até 31 de dezembro de $2015^{\prime \prime}$ (n. ${ }^{\circ}$ ), rapidamente se percebe que as intenções do legislador foram frustradas pelo decurso do tempo e pelas dificuldades de vária ordem (técnica, jurídica, ambiental, social) em proceder à reconversão das AUGI que foram delimitadas um pouco por todo o país mas com particular incidência nas áreas metropolitanas.

E note-se que, ainda que a formulação mais recente da lei das AUGI, datada de 2015, aponte para uma cessação deste regime em 2021, a verdade é que a recente Lei de Bases da Habitação, aprovada pela Lei n. ${ }^{\circ}$ 83/2019, de 3 de Setembro, insiste em referir-se às áreas urbanas de génese ilegal (acoplando esta figura jurídica a uma outra, de contornos mais indeterminados, de núcleos de habitação precária) em algumas das suas disposições (artigo $12 .^{\circ}$, n. $^{\circ} 2$ e artigo $65 .^{\circ}$ ). O que parece ser um claro indicador no sentido da conversão deste regime excepcional num regime regular de ordenamento territorial. Ainda que assim venha a acontecer, pois compreendemos as situações de grande vulnerabilidade que subjazem a algumas

1 Para maiores desenvolvimentos sobre este regime, cf. Fernanda Paula Oliveira, Dulce Lopes, As Áreas Urbanas de Génese Ilegal (AUGIs) no contexto da política de legalização (Coimbra, Almedina, 2016). 
AUGI, julgamos - e antecipemo-lo - que o regime jurídico das AUGI carece de grandes alterações, não só do ponto de vista das metodologias em que assenta, como igualmente do ponto de vista das dinâmicas sociais que alimenta.

Efetivamente o limbo em que muitas AUGI se mantêm durante décadas - como é o caso dos Autos - tem permitido que se consolidem figuras, como a da Administração das AUGI, que deveriam ser constituídas e funcionar de forma provisional, alterando de forma substancial as dinâmicas entre entidades públicas e privadas. De tal forma que não duvidamos que muitas comissões de administração das AUGI se comportam no território como entidades munidas de relevantes competências de natureza pública — com ou sem suficiente base jurídica para o efeito, é isso que discutiremos - e com maiores poderes de facto do que aqueles que usualmente são atribuídos às juntas de freguesia, os verdadeiros centros de proximidade da Administração Pública portuguesa.

Os problemas suscitados pela perpetuação das AUGI, sem reconversão à vista, são ainda agravados, como no caso vertente, com a aplicação ao mesmo território, de vários regimes jurídicos (no caso, o da reabilitação urbana, aprovado pelo Decreto-Lei n. ${ }^{\circ}$ 307/2009, de 23 de Outubro). Nesta situação, as dúvidas que se manifestam nesta matéria prendem-se com as especificidades que estes regimes estabelecem — cada um à sua maneira — quanto: a) às entidades públicas e privadas competentes ou responsáveis em cada regime pelo planeamento, programação e execução das operações relacionadas com a reconversão das áreas urbanas de génese ilegal e com a concretização das áreas de reabilitação urbana; b) às operações concretas que estão cometidas a cada uma daquelas entidades ao abrigo dos respectivos regimes jurídicos, definindo os limites que aquelas regulamentações especiais, funcionalizadas a determinados fins (regularização de grandes ilegais e reabilitação de áreas degradadas), têm relativamente às exigências gerais urbanísticas; e c) às obrigações de financiamento e comparticipação e de adiantamentos que impendem sobre cada uma daquelas entidades, públicas e privadas, no âmbito dos respectivos regimes jurídicos. 


\section{Caraterísticas das aUgi e do seu processo de recon- VERSÃO}

A realidade das áreas urbanas de génese ilegal, que se começou a fazer sentir com alguma acuidade já nos anos sessenta, assumiu particular relevo nos anos seguintes à Revolução de 25 de abril, muito devendo à fragilidade da Administração pública de então e à dificuldade de realojamento dos cidadãos que regressaram, em massa, das ex-colónias.

Mas, mais, a urbanização clandestina é a faceta física de um fenómeno de transformação social mais amplo, que acompanhou a tendência de procura de casa própria ou, mesmo de segundas residências, por vários segmentos populacionais ${ }^{2}$.

Tendo em vista estas motivações iniciais, que relevam no sentido de se tomar em consideração não só as condições de precariedade em que as construções ilegais eram levadas a cabo, mas também as situações de fragilidade pessoal e familiar que as mesmas co-envolviam, tornou-se imperioso instituir mecanismos específicos que permitissem tornar estas situações claudicantes conformes com um adequado ordenamento urbano.

Note-se que não é apenas o fraccionamento físico ilegal — ou a constituição de situações de compropriedade grandemente complexas ${ }^{3}$ - que está aqui em causa. Tratando-se de situações em cascata, como as mesmas não

2 Neste sentido, cfr. Jorge Luís Bruno Soares, "Transformação Informal do Território. Situação na Área Metropolitana de Lisboa”, A Cidade em Portugal: Onde se Vive, Colecção Povos e Culturas, n. ${ }^{\circ}$ 2, Centro de Estudos dos Povos e Culturas de Expressão Portuguesa (UCP, 1997): 345 a 351, e Júlia Susana C. Reis e Maria Teresa Caiado F. Correia, "Lei das AUGI no quadro das alterações ao regime jurídico de gestão territorial- novas soluções para velhos problemas - O PPR", VI Congresso da Geografia Portuguesa Lisboa, 17-20 de Outubro de 2007 (2007): 2-3, http://www.apgeo.pt/files/ docs/CD_VI_Congresso_APG/actas/_fich/61-J\%FAlia_Reis_-_Lei_das_AUGI_no_quadro_das_ altera\%E7\%F5es_ao_regime_jur\%EDdico....pdf

Sobre a evolução do movimento dos clandestinos, respectivas motivações e tipologia dos prédios clandestinos (primeira, segunda habitação, prédios de renda, indústrias e prédios não edificados), cfr. J. Gonçalves, Carla Alves e F. Nunes da Silva, "Do ilegal ao formal: percursos para a reconversão urbana das Âreas Urbanas de Génese Ilegal em Lisboa”, Da Irregularidade Fundiária Urbana à Regularização: Análise Comparativa Portugal-Brasil, L. Bogus. et al. (org.) (S. Paulo: EDUC, 2010): 161-192.

3 Situações estas que, anote-se, na maioria das vezes têm raízes legais, na medida em que a aquisição de avos ou de quotas ideais da compropriedade não era, nem é, genericamente proibida. Proibida era a construção sem o devido título, a partir da entrada em vigor do Regulamento Geral das Edificações Urbanas, e a construção sem a precedência de loteamento, a partir do Decreto-Lei n. ${ }^{\circ}$ 400/84, de 31 de Dezembro. A existência de amplas compropriedades o que dificulta, senão mesmo inviabiliza, é a legalização tanto das construções como da divisão fundiária. 
tinham sido antecedidas do necessário loteamento, não poderiam também obter as competentes licenças ou comunicações de obras de construção, uma vez que não se encontravam preenchidos os pressupostos para a sua concessão (desde logo o da legitimidade sobre o prédio mãe), nem as respectivas autorizações de utilização, o que inviabiliza qualquer acto negocial de compra e venda, arrendamento, constituição de hipotecas ou obtenção de empréstimos sobre os imóveis assim construídos. Foi precisamente para acautelar situações prementes em que a construção era feita sem precedência da prática de qualquer aprovação de loteamento e da realização de obras de urbanização e de edificação, que o legislador veio criar em 1995 um regime excepcional de legalização que se destaca pelo complexo jurídico que o compõe e pelo relevo prático que tem tido.

Como se afirma no Acórdão do Supremo Tribunal Administrativo de 22 de fevereiro de 2005 "a razão de ser do regime excecional de reconversão de áreas urbanas de génese ilegal foi a de permitir às pessoas, normalmente de parcos recursos económicos, ver legalizadas as construções que levaram a cabo para a sua edificação, evitando uma demolição que, em termos normais, seria muito provável, e, por outro lado, permitir a construção em parcelas de terreno adquiridas em que, normalmente, essa construção também não seria possível. Essa possibilidade, há-de, assim, de ser encontrada através da ponderação dos vários interesses em jogo, passando pelo acordo dos vários proprietários, através da cedência, voluntária, ou imposta pela viabilidade do processo, naquilo que seja necessário para a obtenção dos padrões urbanísticos (embora especiais - cfr. artigo 25. ${ }^{\circ}$ da Lei) exigidos" ${ }^{\prime \prime}$.

O âmbito de aplicação do regime jurídico das AUGI incide sobre prédios ou conjunto de prédios contíguos que, sem a competente licença de loteamento, quando legalmente exigida, tenham sido objecto de operações físicas de parcelamento destinadas à construção (até à entrada em vigor do Decreto-Lei n. ${ }^{\circ}$ 400/84, de 31 de Dezembro) - loteamentos ilegais, portanto -, desde que os planos municipais em vigor classifiquem a área onde tais operações têm assento como espaço urbano ou urbanizável (artigo $1 .^{\circ}$, n. ${ }^{\circ}$ 2) ou estas correspondam, na sua maioria, a espaços assim classificados e que a área sobrante

4 Para maior descrição desta situação, cfr. António José Rodrigues, Loteamentos Ilegais - Areas Urbanas de Génese Ilegal - AUGI, 4. ${ }^{\mathrm{a}}$ ed. (Coimbra, Almedina, 2010). 


\section{DULCE LOPES}

esteja ocupada maioritariamente com construções destinadas a habitação própria que preencham condições de salubridade e segurança e se encontrem participadas na respectiva matriz à data da entrada em vigor desta (artigo 5.0.5.

Para além de se tratar de um regime excepcional, como, aliás, a própria lei o qualifica, de legalização, decorre ainda do artigo 57. ${ }^{\circ}$ da Lei n. ${ }^{\circ}$ 91/95 ser este um regime com uma natureza transitória.

É por isso, e esta nota é particularmente importante no caso dos Autos, intenção do legislador que a ilegalidade resultante das AUGI seja resolvida em certo prazo e não mantida indefinidamente, tal como não deve ser mantido ad aeternum o regime excepcional previsto no diploma. $\mathrm{E}$, mesmo que o prazo de vigência do diploma das AUGI e das soluções nele constantes venha a ser de novo prorrogado, a verdade é que o mesmo foi criado para viabilizar ou facilitar um objectivo de interesse público (e simultaneamente privado): o da regularização fundiária, sendo que é por via desta que se conseguirá a legalização dos usos e edificações existentes na AUGI ou de outros que aí sejam incluídos, e a conformação destes com os ditames de ordenamento do território e de urbanismo aplicáveis.

Caso não se regularizem as AUGI, como é intenção do legislador, manter-se-á uma situação que, como veremos, pode conduzir a situações de indefinição de responsabilidades e a uma indistinção de funções, bem como a um clima de descrédito que já se instalou quanto à concretização de muitos processos de reconversão das $\mathrm{AUGI}^{6}$.

Também no que ora interessa, o regime das AUGI é um dos exemplos mais marcantes da intersecção entre as regras do direito do urbanismo e das regras jus-civilistas que regem os poderes de disposição da propriedade.

5 Exige, porém, o artigo $5 .{ }^{\circ}$ que, neste caso, se tenha de alterar o plano em vigor de modo a que toda a AUGI passe a coincidir com solo classificado como urbano ou urbanizável (n. 3 do artigo $5 .^{\circ}$ ).

6 Sobre o clima de descrédito e desânimo que se instalou na primeira década deste milénio, cfr. Isabel Raposo e Ana Valente, "Diálogo social ou dever de reconversão? As Áreas Urbanas de Génese Ilegal (AUGI) na Área Metropolitana de Lisboa”, Revista Critica de Ciências Sociais, N. 9 (Dezembro, 2010): 225, que o veem como consequência "do arrastar dos processos; da consciência crescente do tempo longo da reconversão, apesar da Lei excepcional; da dificuldade de ultrapassar os entraves urbanísticos (condicionantes e classes de espaço dos Planos Directores Municipais em vigor); da lentidão inerente à complexificação normativa dos instrumentos de gestão territorial; da burocrática teia de legalização fundiária; da rotina repetitiva e pouco estimulante; do cansaço dos proprietários e dos responsáveis das $\mathrm{CAC}$ que se consomem em penosos processos burocráticos normativos e jurídicos muitas vezes kafkianos". 
Isto é assim porque a regularização destas áreas de génese ilegal passa, por um lado, por uma sua regularização urbanistica - através, precisamente, de instrumentos tipicamente urbanísticos como são a operação de loteamento e os planos de pormenor - e, por outro lado, por uma regularização fundiária do direito de propriedade (ou de outros direitos fundiários), com apelo a instrumentos típicos de direito civil e de direito processual civil (como é o caso da ação de divisão de coisa comum, ainda que dotada de necessárias especificidades, até porque só pode ser concretizada após a emissão do título de reconversão - cfr. artigo $\left.2 .^{\circ}\right)$.

É a conjugação destes dois tipos de exigências e destes dois tipos de regimes que torna o regime das AUGI altamente complexo e nem sempre de fácil manuseamento.

No que ora, releva, os prédios integrados na AUGI estão, até ao termo da execução do processo de reconversão ${ }^{7}$, sujeitos a um regime de administração conjunta assegurada pelos proprietários ou comproprietários.

A administração conjunta - inscrita no Registo Nacional de Pessoas Colectivas não tem personalidade jurídica, mas detém capacidade judiciária e legitimidade ativa e passiva nas questões emergentes das relações jurídicas em que seja parte —, integra, como órgãos, uma assembleia de proprietários ou comproprietários, uma comissão de administração e uma comissão de fiscalização, cujas composição, competências, funcionamento e gestão financeira se encontram definidas nos artigos $8 .^{\circ}$ a $16 .^{\circ}-\mathrm{C}$.

Em causa está, não apenas, uma regulamentação destinada a disciplinar a relação entre os proprietários ou comproprietários durante todo o processo de reconversão (uma regulamentação destinada, portanto, a regular relações estritamente privadas), mas também dirigida a definir os poderes e os trâmites da responsabilidade dos proprietários e comproprietários na regularização (reconversão) urbanística da área e sua execução bem como na regularização jurídica da mesma de acordo com os instrumentos urbanísticos devidamente aprovados (dirigida, assim, a regular aspetos publicistas das relações em causa).

7 De facto, nos termos do artigo $17 .^{\circ}, \mathrm{n} .^{\circ} 1$, a administração conjunta extingue-se após a receção definitiva das obras de urbanização pela câmara municipal e a aprovação das contas finais da administração. 


\section{DULCE LOPES}

Para efeitos da Administração conjunta impõe a lei, em especial no que concerne ao seu órgão deliberativo - a assembleia de proprietários ou comproprietários - que a mesma seja composta por quem efetivamente se comporta como proprietário dos prédios nela integrados.

Esta intenção do legislador determina, deste modo, uma composição particular de tal assembleia, impedindo que os particulares que figuram como proprietários no registo predial mas que assumiram a posição de loteadores ilegais, se possam prevalecer desta sua actuação fraudulenta para dela retirar benefícios ${ }^{8}$.

Determina então o artigo $90^{\circ}$ do regime jurídico das AUGI's que têm assento na assembleia os proprietários ou comproprietários cujo direito esteja inscrito na conservatória, exceto nas situações em que são substituídos pelos donos das construções erigidas na área da AUGI, devidamente participadas na matriz e dos promitentes-compradores das parcelas, havendo tradição. O que, só por si, evidencia o regime especial de legitimidade em que assenta a AUGI e que, por isso, só pode valer para os efeitos específicos determinados nessa legislação. Nas demais situações valerá o regime geral da compropriedade.

De acordo com o disposto no artigo $4 .^{\circ}$ da Lei das AUGI, o processo de reconversão pode ser organizado como operação de loteamento da iniciativa dos proprietários ou comproprietários ou como operação de loteamento ou plano de pormenor municipal ou intermunicipal da iniciativa da respectiva câmara municipal ou das câmaras municipais associadas para o efeito, regendo-se estas actuações pelo especialmente disposto no diploma das AUGI e, subsidiariamente pelo previsto, respectivamente, no regime jurídico da urbanização e edificação e no regime jurídico dos instrumentos de gestão territorial.

A reconversão de iniciativa municipal pode ser feita por intermédio de operação de loteamento ou de plano de pormenor municipal ou intermunicipal (quando, neste caso, a área territorial a reconverter esteja situada em municípios distintos), em ambos os casos, com ou sem apoio da administração conjunta (artigo $31 .^{\circ}$ e seguintes).

Já a reconversão com apoio e sem apoio da Administração conjunta prende-se com o papel que a administração conjunta (em especial a comissão de

8 Sobre a especial posição dos loteadores ilegais no diploma das AUGI, cfr. o artigo 45. . 
administração) pretende desempenhar no processo. No primeiro caso, é celebrado um contrato de urbanização que delimita as atribuições e âmbito de intervenção da câmara municipal e da comissão de administração (podendo esta assumir um papel coadjuvante precioso, desde logo na recolha de elementos, de transmissão de informações, etc., mas sendo sempre o município o dominus do processo); no segundo, o município assume todas as tarefas decisórias e administrativas, apenas contando, sendo caso disso, com a adesão ao processo de alguns proprietários individuais (artigo 32. ${ }^{\circ}$ ).

Em qualquer caso, porém, de reconversão por iniciativa municipal, a decisão sobre o cenário da reconversão (incorporado numa operação de loteamento ou num plano de pormenor) é uma decisão municipal, relativamente à qual a Assembleia de comproprietários não se pode opor, já que a lei apenas lhe comete a responsabilidade de avaliar e não de aprovar "a solução urbanística preconizada, na modalidade de reconversão por iniciativa municipal" [cfr. artigo $10 .^{\circ}$, n. $^{\circ} 2$, alínea e)]. Mas isto sem que os comproprietários se possam desonerar do pagamento das comparticipações nos encargos de urbanização, que serão assegurados nos termos dos artigos $26 .^{\circ}$ e $27 .^{\circ}$ da Lei das AUGI e a que nos referiremos adiante.

Os processos em apreço são claramente distintos consoante o tipo de modalidade de reconversão pelo que se opte. Daí que nos cause extrema estranheza a circunstância de, desde que a AUGI do BFV em causa nos presentes Autos foi delimitada, nunca tenha havido a preocupação de definir, pelo menos de modo explícito, a modalidade de reconversão aplicável, o que constitui uma das questões que foi submetida a apreciação pelo Tribunal. Este entendeu, nesta parte, que a não fixação da modalidade da reconversão não constitui uma nulidade do processo, pois ainda que a lei diga que ela tem de ocorrer; não decorre que essa fixação tenha que ocorrer na data ou na deliberação que delimita a AUGI. Segundo o Acórdão em comentário, de 2018, não se vê "que essa fixação não possa ocorrer num momento posterior; de qualquer modo, $\mathrm{o}$ que não ocorre, com certeza, é a nulidade do processo por falta da fixação da modalidade, pois que não há norma que diga que essa não fixação tem como consequência a nulidade”. Contudo, acrescentamos nós, a correta condução dos processos de reconversão não se analisa apenas no binómio validade/ invalidade; é necessário acautelar a adequada condução dos procedimentos 
administrativos para conseguir dar passos decisivos e seguros no sentido da regularização pretendida pelo legislador.

Não concebemos, ao contrário do Acórdão do Tribunal da Relação de Lisboa em comentário, que possa inexistir uma modalidade de reconversão válida e eficaz para a AUGI, uma vez que tal conduziria a uma lacuna inadmissível quanto às formas de reconversão e títulos de reconversão aplicáveis ao caso. Em bom rigor, tal equivale a reconhecer que não existe uma qualquer linha de rumo traçada para a regularização da AUGI do BVF, o que a torna numa AUGI com objecto mas sem objectivos e sem objectividade.

E se achamos que essa linha de rumo de facto é muito débil, entendemos que a mesma deve existir, nem que seja para que possamos ajuizar, como os demais intérpretes do Direito, quais as regras que devem ser mobilizadas para resolver situações de elevada complexidade como a vertente.

Uma coisa é certa, no caso da AUGI do BVF, não há ainda um título de reconversão. Mas mais do que isso, nunca houve um projecto de reconversão que possa assumir essa designação, uma vez que o projecto de loteamento apresentado nunca passou pelo crivo da Assembleia de proprietários e comproprietários, nem existe um plano de pormenor aprovado para o local (apenas o plano diretor municipal e um plano de urbanização, que veem a área como de manutenção provisória até à sua reconversão).

Existe apenas, a nosso ver, aquilo que se designa por antecedentes procedimentais, isto é estudos, tanto da comissão de administração, como da própria Administração municipal que tendem para a regularização da AUGI, mas que não se encontram suficientemente concretizados para que se possa, com a devida segurança e ponderação de todos os interesses envolvidos, definir o efectivo projecto daquela regularização.

Trata-se por isso, do ponto de vista jurídico, de um momento ainda muito incipiente no processo de regularização o que, como veremos, terá de se reflectir na consolidação da posição jurídica da Administração Conjunta, em especial na possibilidade da Assembleia de proprietários e comproprietários deliberar sobre comparticipações e da Comissão da Administração as exigir. 


\section{REgIME JURÍdico DAS ARU}

Antes de nos debruçarmos sobre o regime jurídico da reabilitação urbana, é mister tecermos algumas considerações sobre a área crítica de recuperação e reconversão urbanistica para a área (ACCRU), aprovada à luz do Decreto 794/76, de 5 de Novembro.

De acordo com este diploma, já revogado, «poderão ser declaradas áreas críticas de recuperação e reconversão urbanística aquelas em que a falta ou insuficiência de infra-estruturas urbanísticas, de equipamento social, de áreas livres e espaços verdes, ou as deficiências dos edifícios existentes, no que se refere a condições de solidez, segurança ou salubridade, atinjam uma gravidade tal que só a intervenção da Administração, através de providências expeditas, permita obviar, eficazmente, aos inconvenientes e perigos inerentes às mencionadas situações» (artigo 41. $\left.{ }^{\circ}, \mathrm{n} .^{\circ} 1\right)$. De acordo com esta definição, a delimitação de uma ACCRU visa proceder a uma intervenção expedita e em moldes impositivos (coercivos) numa área degradada.

Por esse motivo, os únicos instrumentos estipulados naquele Decreto são os da expropriação por utilidade pública urgente, da tomada de posse administrativa como meio para a ocupação temporária de terrenos, a demolição de edifícios com caráter de urgência ou para a realização de obras de beneficiação e reparação de edifícios. Ao que acrescia a possibilidade de se estabelecer o direito de preferência ao Município (artigo 27..$^{\circ}$ n. ${ }^{\circ} 1$ da Lei dos Solos).

Ora, apesar de a ACCRU não prever a planificação da sua área de intervenção, permitia que o Município interviesse em situações que carecessem de urgente intervenção, o que demonstra que nas mesmas o interesse público tinha manifesta prevalência sobre o interesse privado. Todavia, não é um mecanismo que tendesse para ou procedesse à regularização fundiária da área de intervenção, apenas permitindo resolver situações que carecessem de iminente ação pública, designadamente por via expropriativa (mecanismo este que, adiante-se, não se encontra previsto, pelo menos explicitamente, no regime jurídico das AUGI).

A ACCRU posteriormente foi convertida numa área de reabilitação urbana, nos termos do artigo $78 .^{\circ}$ do regime jurídico da reabilitação urbana, passando este a aplicar-se à área em apreço 9 .

9 De acordo com o n. ${ }^{\circ} 5$ deste artigo "os decretos de classificação de áreas críticas de recuperação e 
Se, porém, aquelas áreas críticas tinham por base um paradigma de intervenção casuísta, já as áreas de reabilitação urbana assentam em pressupostos diferenciados: os da programação das intervenções da Administração e de privados no território, através da aprovação de uma estratégia ou de um programa estratégico de reabilitação urbana, que defina o tipo de atuações (de reabilitação e regeneração) a concretizar.

A reabilitação urbana, regime assente na delimitação de áreas de reabilitação urbana (preenchidas por operações de reabilitação urbana), visa o cumprimento de um conjunto muito variado de objectivos - físicos, funcionais, ambientais e sociais - tendentes à intervenção sobre áreas dominantemente construídas e consolidadas, o que denota o seu carácter complexo.

Objetivos estes que vão muito para além de mera reabilitação dos edifícios, visando a intervenção integrada sobre o tecido urbano existente. Assume-se a reabilitação urbana como uma política pública, no sentido de uma actividade predominantemente racional e, em certa medida, técnica, dominada por objectivos pré-seleccionados por uma vontade política, caracterizada por uma hierarquização segundo determinadas prioridades e por uma escolha dos meios mais aptos à satisfação das finalidades formuladas pelos decisores políticos ${ }^{10}$. Esta é a consequência - ainda que se considere ser um dever dos proprietários assegurar a reabilitação urbana dos seus edifícios e fracções (designadamente por intermédio da realização das obras necessárias à manutenção ou reposição da sua segurança, salubridade e arranjo estético) —, de se determinar que a adopção das medidas necessárias à reabilitação das áreas que delas carecem é uma incumbência de entidades públicas (do Estado, das Regiões Autónomas e das autarquias locais: artigo $5 .^{\circ}$ do presente diploma).

A identificação, bastante exaustiva, dos objectivos para os quais a reabilitação urbana deve contribuir, previstos no artigo $3 .^{\circ}$ do Regime Jurídico da Reabilitação Urbana é bem prova disso, já que é possível reconduzir grande

reconversão urbanística, praticados ao abrigo do Decreto-Lei n. ${ }^{\circ} 794 / 76$, de 5 de novembro, alterado pelos Decretos-Leis n.os 313/80, de 19 de agosto, e 400/84, de 31 de dezembro, caducam caso não venha a ser aprovada, nos termos e prazo previstos nos números anteriores, a conversão de área crítica de recuperação e reconversão urbanística em áreas de reabilitação urbana”. No caso, tendo-se dada esta conversão, as regras a aplicar passarão a ser as do regime jurídico da reabilitação urbana. Sendo que, com esta conversão, deixaram de ser aplicáveis aqueles diplomas, nos termos do . $^{\circ} 7$ do artigo $80 .^{\circ}$.

10 Cfr. Maria Adelaide Teles de Menezes Correia Leitão, "O Planeamento Administrativo e a Tutela do Ambiente”, Revista da Ordem dos Advogados, Ano 56, Janeiro de 1996, nota 26. 
parte deles a objectivos de outras políticas públicas com as quais a reabilitação urbana mantém especiais relações (política urbanística e de ordenamento territorial, ambiental e de mitigação de riscos, de preservação e promoção do património cultural).

O que significa acima de tudo que a reabilitação urbana (e a sua extensão - a regeneração urbana) são assumidas como funções públicas a ser garantidas pelas entidades públicas, ainda que com participações variadas dos privados, em especial dos proprietários da área de intervenção. E isto sobretudo quando em causa estejam operaçôes de reabilitação urbana sistemática, nas quais mais do que a incidência sobre o edificado existente, em que as responsabilidades privadas são mais evidentes, se pretende a concretização de obras de remodelação, beneficiação ou reabilitação dos sistemas de infra-estruturas urbanas, de equipamentos e de espaços verdes de utilização colectiva existentes que se apresentem como insuficientes ou degradados (ou na sua criação quando inexistentes), com vista à revitalização do tecido urbano, independentemente de se encontrarem ou não associados à reabilitação do edificado existente na zona (artigo 8..$^{\circ}$ ). Estas operações de reabilitação urbana sistemática, encontram-se sempre associadas a um programa de investimento público e, por isso também, a um especial papel das entidades públicas na sua concretização.

Por isso mesmo, a ARU a que nos reportamos, ao ter resultado da conversão de uma ACCRU e ao ter assumido a caracterização de uma ARU sistemática, denota claramente a imprescindibilidade de intervenção pública, seja de programação, seja financeira, na área em apreço. O que é igualmente confirmado pelo facto de a gestão ser assegurada pelo Município (enquanto entidade gestora, de acordo com os artigos $8 .^{\circ}$ e $9 .^{\circ}$ do regime jurídico aplicável), e por a execução ser feita por iniciativa e por execução direta desta entidade gestora (artigo 11. ${ }^{\circ}$ ).

É esta entidade, portanto, que terá a responsabilidade pública de assegurar a programação e a execução do programa estratégico de reabilitação urbana que definiu exigindo que este cumpra todas as exigências legais aplicáveis.

Acrescente-se que tendo havido lugar a esta ARU, preenchida por uma operação de reabilitação urbana sistemática, foram fixadas pelo Município de $\mathrm{O}$ as intervenções de regeneração/reabilitação urbana que fazem sentido, 
do ponto de vista do interesse público, na qualificação do espaço, no âmbito territorial daquela ARU.

O que significa que, do ponto de vista da reabilitação urbana, as medidas inscritas no programa estratégico se assumem como aquelas e apenas aquelas que, para o Município, surgem como importantes e «urgentes» para a regeneração de um espaço que, assinale-se, ainda não foi objecto de regularização urbanística e fundiária.

A este propósito, deve adicionalmente fazer-se uma referência aos modelos de associação com privados previstos e admitidos no âmbito das operações de reabilitação urbana que se executem por iniciativa das entidades gestoras (maxime por se tratarem de operações de reabilitação urbana sistemática), uma vez que é a própria ARU que estabelece que, ainda que o modelo de execução a adoptar seja o da iniciativa da entidade gestora, através da execução direta pela entidade gestora, pode, no entanto, optar-se pela execução através de administração conjunta (da ARU) e parcerias com entidades privadas.

O que nos remete para uma eventual execução da ARU com o apoio da Administração conjunta, tertium non datur. Ora, a Administração conjunta permite que a entidade gestora possa executar a operação de reabilitação urbana, ou parte dela, em associação com os proprietários e titulares de outros direitos, ónus e encargos relativos aos imóveis existentes na área abrangida pela operação de reabilitação urbana (artigo $40{ }^{\circ}$ do Regime Jurídico da Reabilitação Urbana). No entanto, esta disposição nunca foi regulamentada pelo que permanece de duvidosa aplicabilidade ${ }^{11}$, o que de certa forma se compreende dada a possibilidade de o Município poder seleccionar alguns parceiros em detrimento de outros - ainda que estejam em causa proprietários na área -, o que pode suscitar dúvidas sobre a transparência, imparcialidade e objectividade da atuação da Administração municipal.

Não obstante, mesmo que se admita que a Administração conjunta (entenda-se da ARU) corresponde à Administração conjunta da AUGI, por esta se encontrar especialmente regulada em lei avulsa, e que a esta podem ser cometidas responsabilidades de execução da ARU, nos termos contratualizados, haverá sempre que analisar os moldes dessa contratação, de modo a aferir se

11 Para críticas a esta ausência de regulamentação, cf. Fernanda Paula Oliveira, Dulce Lopes e Cláudia Alves, Regime Jurídico da Reabilitação Urbana (Coimbra, Almedina, 2011): 175-176. 
e em que medida a Administração conjunta da AUGI pode ser chamada a comparticipar projectos de reabilitação em áreas que ainda não são legais e que não se sabe, dado o estado incipiente do projecto, se o virão a ser.

Além do mais, a aceitar-se que alguma entidade seja parceira da Administração nos processos de reabilitação, ela terá de ser a Administração conjunta e não quaisquer entidades privadas, como associações de moradores ou de interesses que tenham vindo a ser criadas ou a desenvolver-se na área da AUGI. Quanto a estas não há qualquer motivo para que sejam chamadas a desembolsar fundos associativos ou a beneficiar de fundos públicos para o exercício das suas actividades puramente privadas ${ }^{12}$.

E, ainda assim, essa associação entre ARU e AUGI tem de ser vista dentro dos limites das responsabilidades da Administração conjunta, não as podendo exceder. Assim, há que ter sempre em linha de conta que Administração conjunta, ainda que seja instituída por iniciativa de qualquer proprietário, comproprietário ou da câmara municipal, corresponde a uma entidade legislativamente prevista e regulada que cumpre uma função própria e indelegável (cfr. artigo $10 .^{\circ}$, n. 3 ); que apenas deve agir em estrita aplicação da lei das AUGI e no que nela for admitido como pertinente à sua regularização (legalização física e fundiária) e não para prosseguir finalidades mais amplas como as de um melhoramento genérico da área do ponto de vista dos espaços verdes ou equipamentos (isso é uma tarefa municipal, que não pode, a nosso ver, ser imputada como "dever" à Administração conjunta). E, acentue-se, a administração conjunta, não tendo personalidade jurídica, ainda que detenha capacidade judiciária e legitimidade ativa e passiva nas questões emergentes das relações jurídicas em que seja parte, não pode, desde logo, ser proprietária de bens, seja na área da AUGI seja em qualquer outra área, o que significa que, como parceira da Administração, sempre terá uma mais valia muito limitada na execução das operações da ARU.

Assim, a circunstância de o legislador da reabilitação urbana ter admitido a execução por associação com a Administração Conjunta (sem, todavia, nunca

12 De facto, se se percebe que o Município, numa área de reabilitação urbana e para cumprimento dos objectivos desta conte com a única Administração conjunta (constituída com exclusão de qualquer outra para a área), já não poderá, sem mais fundamentação e argumentação, assumir que uma qualquer associação de direito privado, por muito que esteja enraizada no local em apreço, é a única que tem capacidade para titular ou explorar um equipamento considerado de interesse público, previsto naquela ARU. 
ter regulamentado esta hipótese, nem sequer mencionado expressamente que esta Administração era ou poderia ser a Administração das AUGI), não legitima que se considere transferida para aquela a responsabilidade na execução e financiamento das opções públicas de reabilitação/regeneração urbana. Estas serão responsabilidades públicas e, por isso, devem ser assumidas pelas entidades públicas, apenas podendo ser comparticipadas ou assumidas directamente por terceiros dentro dos limites que o regime jurídico a estes aplicáveis dita.

Caso, no âmbito deste regime da AUGI, não seja possível que a Administração Conjunta assuma encargos com operações que estão fora do seu modelo de atuação, funcionalizado à regularização urbanística e fundiária, restará ao Município ressarcir-se das formas que lhe estão genericamente disponíveis: através da procura de financiamentos, de taxas urbanísticas, de compensações, ou de participação no produto arrecadado de impostos municipais como o imposto municipal sobre imóveis.

\section{AUGI E ARU: CRUZAMENTOS NO CASO VERTENTE}

Tendo em conta estas linhas divisórias e tudo o que foi previamente explicitado, há que aferir em que medida o nosso iter se compagina com a argumentação expendida no douto Acórdão do Tribunal da Relação de Lisboa, em comentário. Neste foi desde logo considerado que o Município não fixou a modalidade de reconversão nos termos do artigo $4 .^{\circ}$ da Lei das AUGI (por esta nunca ter sido publicada $)^{13}$, bem como que a assembleia de proprietários e comproprietários nunca aprovou formalmente os mapas de comparticipações nem os respectivos métodos e fórmulas de cálculo.

Considera esta Instância jurisdicional, como resulta do artigo $1 .^{\circ}, \mathrm{n} .^{\circ} 1 \mathrm{da}$ Lei das AUGI, que este regime é excepcional prevalece sobre quaisquer outras normas jurídicas potencialmente aplicáveis e que podem com ele estar em desconformidade. De onde conclui que «irreleva, no caso, a coincidência de áreas abrangidas pela AUGI e pela área de reabilitação urbana, soçobrando,

13 No entanto, mais tarde, o Tribunal entende que a aplicação do disposto no art. $26 .^{\circ}$, n. ${ }^{\circ} 3$ da Lei das AUGI, pressupõe que está definida a modalidade de reconversão por iniciativa dos particulares, o que é, para nós, uma contradição nos termos. 
pois, toda a argumentação invocada pelos executados relacionada com a aplicação do regime jurídico da reabilitação urbana ».

Mais acrescenta que não há incompatibilidade de ARU com AUGI. Esta visa legalizar uma ilegalidade e a primeira visa «recuperar ou reabilitar um ou mais prédios pressupondo que eles já estão legais ou vão ser legalizados. Portanto, reabilitam-se prédios, sem prejuízo de se poder ainda estar a legalizar esses mesmos prédios».

Ou seja, de acordo com o douto Tribunal pode haver lugar a intervenção em edifícios ilegais ou em situações ilegais dentro da noção de reabilitação, o que significa que esta pode consolidar as ilegalidades, criá-las ou agravá-las, sem que o Tribunal identifique qualquer filtro aplicável a esta possibilidade.

Ora, ainda que AUGI e ARU não sejam realidades inconciliáveis, a verdade é que são realidades dificilmente conciliáveis, uma vez que os respectivos regimes não apontam sempre e/ou harmoniosamente no mesmo sentido, ao contrário do que parece depreender-se do Acórdão em análise.

A haver necessidades de reabilitação urbana na área vertente - relembre-se, uma área ilegal sem título de reconversão aprovado —, as mesmas apenas podem ser satisfeitas caso isso corresponda a um interesse público imperioso e urgente e não apenas a uma intenção de qualificação do espaço (como poderia acontecer noutros bairros, de matriz legal) ou a uma "necessidade" de aproveitamento de fundos públicos, nacionais ou comunitários que se mostram disponíveis. Isto porque aquela reabilitação vai ter como efeito a criação de novas ilegalidades por força da atuação administrativa, que a ARU não pode ignorar mas que isoladamente não consegue resolver, sem que seja aprovado o título de reconversão para a AUGI.

Ou seja, não se podem "reabilitar prédios" (noção esta entendida de forma amplíssima pois, no caso, a pretensa reabilitação consistiu na criação de novas infra-estruturas e equipamentos e não na requalificação dos preexistentes) independentemente da sua natureza legal ou ilegal. Esta qualificação tem de permear a própria política de reabilitação urbana de que se parta e é por isso que é o Município a única entidade que pode assumir o papel de entidade promotora e gestora da operação sistemática em apreço.

Desde logo porque nunca a Administração conjunta o poderia fazer, já que estaria a fazer obras para as quais não teria legitimidade, pois estaria a 
executar a operações urbanísticas de realização de obras de urbanização e de obras de edificação para as quais não se encontra legalmente mandatada (ao que mais tarde aludiremos) e para as quais não dispunha, nem podia dispor, de título administrativo bastante.

Assim, se é o Município que "desbloqueia" as presentes obras, apresentando-se como a entidade gestora da ARU, também tem de ser ele a assumir a responsabilidade pelas situações em que não esteja em causa uma estrita regeneração urbana (a intervenção sobre o existente para manter as suas condições de funcionamento) mas sim a criação de novos espaços e infra-estruturas que agravem as ilegalidades verificadas, dificultando ainda mais a criação das condições de regularização urbanística e fundiária do espaço. Naturalmente que este tipo de atuações não podem ser responsabilidade da Administração conjunta da AUGI, que tem como missão legal exclusiva reconverter uma situação de ilegalidade que deveria estar bem definida à partida e não contribuir para a sua descaracterização.

\section{REPARTIÇÃO DE RESPONSABILIDADES E ENCARGOS}

Feitas as precisões sobre o estatuto jurídico da área do BVF, que se encontra no cruzamento entre dois regimes legais particulares: o das AUGI e o das ARU, há que deles retirar consequências no que se refere às responsabilidades das entidades públicas e privadas envolvidas, em especial no que se refere às comparticipações e adiantamentos que os membros da Administração conjunta da AUGI têm vindo a ser chamados a desembolsar.

Julgamos ter deixado já claro que comunhão de fins não significa indistinção de funções entre entidades (públicas e privadas), muito menos pode significar que aquelas entidades públicas deixem de cumprir as suas responsabilidades e que estas entidades privadas passem a ter competências e a assumir encargos que vão muito para além do que lhes é legalmente exigível.

E se é certo que o dever de reconversão que impende sobre os proprietários e comproprietários na área das AUGI inclui o dever de comparticipar nas despesas de reconversão, esta comparticipação é apenas devida "nos termos fixados na presente lei" (artigo $3 .^{\circ}$, n. ${ }^{\circ} 3$ ). 
Esta limitação é extremamente importante uma vez que as consequências do não cumprimento deste dever podem ser bastante gravosas, pois, para além da possibilidade de execução dos montantes em dívida, os encargos com a operação de reconversão gozam do privilégio imobiliário previsto no artigo $743 .^{\circ}$ do Código Civil, sendo graduados logo após a hipoteca prevista no n. ${ }^{\circ}$ 3 do artigo $27 .^{\circ}$ (por falta de prestação de caução). Assim, é possível que do não cumprimento das comparticipações devidas - e apenas destas - resulte a perda do direito que com o processo de reconversão se pretendia fazer valer.

Por isso mesmo o entendimento jurisprudencial que nos últimos anos tem prevalecido quanto às comparticipações devidas pelos proprietários e comproprietários da Administração conjunta é, e adequadamente, restritivo, sobretudo no que se refere ao custeio de obras de urbanização.

De facto, de acordo com o Ac. Rel. Évora, de 9-09-2009 (P. 1783/08-2, in www.dgsi.pt), só após o instrumento de reconversão (operação de loteamento) é que se pode exigir aos comproprietários o pagamento da sua comparticipação nas despesas de reconversão para execução dessas obras (só assim não será relativamente às despesas de funcionamento da comissão de administração, para execução dos projectos e acompanhamento técnico do processo).

Suporta-se esta posição na Lei das AUGI, seja no artigo $10 .^{\circ}, \mathrm{n} .^{\circ} 2$, alínea d), que se refere à reconversão por loteamento, não existindo ainda alvará no caso apreciado pelo Tribunal da Relação de Évora, tendo apenas a Câmara Municipal admitido liminarmente o pedido de licenciamento. Também de acordo com o artigo $18 .^{\circ}, \mathrm{n} .^{\circ} 2$, alínea b) daquela Lei, só após a aprovação do loteamento é apresentado na câmara municipal o orçamento das obras de urbanização previstas e o mapa contendo o valor absoluto e a quota de comparticipação de cada lote nos custos de execução das obras e da caução legal, nos termos do $n .^{\circ} 3$ do artigo $26 .^{\circ}$. Concluindo, por isso, que, quando o artigo $15 .^{\circ}, \mathrm{n} .^{\circ} 1$, alínea c) da referida lei alude às despesas com a execução das obras de urbanização, estas só podem ser aquelas que foram alvo dos projectos aprovados, até porque se o fossem antes nada garantiria que esta aprovação viesse a ocorrer.

Adianta este Tribunal que, mesmo que assim não se entendesse, “a obrigação relativa às despesas com a execução de obras de urbanização era inexequível" pois, não tendo sido aprovado o projecto de urbanização "desconhece-se 
a área do loteamento e do lote que irá ser atribuído aos executados, bem como a respectiva área de construção, elementos esses que irão constar do respectivo alvará”.

O juízo subjacente a esta decisão tem colhido os seus frutos nos Tribunais, tendo, porém, mais recentemente, o Acórdão do Tribunal da Relação de Lisboa em comentário, bem como a decisão de primeira instância que o precedeu, ido em sentido diametralmente oposto, ao admitir que sejam imputáveis à Administração conjunta todo o tipo de despesas que mais directa ou mais remotamente tenham a ver com a área de intervenção da AUGI.

Por isso, admite, como referido no $n .^{\circ} 1$ da cláusula $11 .^{\circ}$ do contrato para a elaboração do Plano de Urbanização da Vertente Sul do Concelho de $\mathrm{O}$, que os custos com o Plano de Urbanização, Avaliação ambiental e Programa de Ação Territorial corra pelas AUGI, podendo aquelas despesas assim contratualizadas ser vistas como perfeitamente legítimas e justificadas.

Perante a alegação dos executados de que não só não se perspectivava a legalização da AUGI, como ainda de que as comparticipações que se encontravam a ser solicitadas pela Comissão com base em tarefas, actos e contratos que se reportam a atuações não cobertas pela lei das AUGI, sem que fossem calculadas em função de regras de proporcionalidade que subjazem a este regime jurídico, o Tribunal referido entende que o critério usado «é um critério como qualquer outro, que não se revela em abstracto como desproporcional nem arbitrário».

Este Tribunal admite ainda, quanto às infra-estruturas, que, apesar de as normas legais do regime da AUGI, que transcreve sem explicitar, poderem «ser lidas de acordo com as duas interpretações, a verdade é que elas são mais compatíveis com a versão de que as despesas de reconversão vão sendo feitas ao longo de todo o processo e não na fase final do mesmo, designadamente as infra-estruturas básicas (redes viárias, de electricidade, de águas, de esgotos) em princípio estarão feitas antes da parte final, para que os comproprietários tenham podido viver com o mínimo de condições durante todo o processo. $\mathrm{E}$ os órgãos da AUGI existirão para fazerem, ou participarem ou ajudarem em obras ao longo do processo - daí as contas anuais — e não para dar origem a despesas burocráticas com o seu próprio funcionamento improdutivo». Para o efeito, para além de dar conta de situações em que houve decisões 
judiciais que vieram a considerar legítimas as despesas com obras de reconversão mesmo antes da existência do processo de reconversão ${ }^{14}$, considera que é um contra-senso não as admitir pois é normal que sejam os compradores ou construtores de obras que realizem ou paguem aquelas infra-estruturas e não terceiros. Além de que se assim não fosse também seria um absurdo pagarem-se as despesas com a administração de uma entidade que nada (ou pouco) faria.

Esta decisão judicial merece as nossas mais severas críticas, uma vez que abraça uma lógica do facto consumado, na qual parece que é irrelevante que haja uma qualquer política de contenção (e de reconversão) das situações ilegais que se verificam na AUGI. Isto porque seria sempre legítimo à Comissão da AUGI, para justificar a sua própria existência (caso contrário seria uma criação inútil, como alude o Tribunal), fazer todo o tipo de obras, como se se tratasse de um promotor imobiliário privado qualquer.

Sem entrarmos ainda na leitura do Regime Jurídico das AUGI que é, julgamos nós, inconciliável com o entendimento subjacente a este Aresto, devemos desde já acentuar que a Comissão da AUGI e, mais genericamente, a Administração conjunta, não se podem comportar como promotores imobiliários que visam o "normal" desenvolvimento urbanístico das suas propriedades. A sua responsabilidade legal é tão-só a de reconverter a AUGI, revertendo a situação de ilegalidade e não permitir antecipadamente a sua consolidação, senão mesmo o seu agravamento, antes do título de reconversão ser aprovado.

E, veja-se, que, mesmo que se comportassem como promotores privados, os mesmos teriam de submeter os seus projectos a apreciação municipal de acordo com as regras previstas no Regime Jurídico da Urbanização e Edificação, regime este que exige que as obras de urbanização sejam subsequentes a um loteamento, sempre que este exista. Requisito este que no caso não está cumprido.

Ou seja, mesmo equiparando-se a posição da Administração conjunta da AUGI a qualquer outra situação urbanística, nunca poderia a AUGI ter

14 Note-se que a mais relevante delas - o Acórdão Rel. Lisboa, de 9-11-2017, proferido no processo 3844/13.=TCLRS.L1-6, in www.dgsi.pt veio a ser revogada pelo Ac. STJ, de 27-10-2018 (P. 3844/13.0TCLRS.L1.S1) em sede de recurso de revista. A ela voltaremos mais tarde. 
liberdade absoluta para fazer as obras que considere necessárias na respectiva área. Quando muito o que deve suceder - e é assim que se tem vindo a enquadrar situações que, por razões sociais e de condições mínimas de habitabilidade o exigem - é que o Município procede à execução antecipada de obras de urbanização que depois imputa aos proprietários e comproprietários (ou então assume diretamente esses mesmos custos). Possibilidades estas inclusive previstas nos artigos 50..$^{\circ}$ e 50.-A da Lei das AUGI.

No caso vertente, poderia mesmo assumir-se que algumas das operações previstas na ARU visam, precisamente, dotar as AUGI destas condições de habitabilidade e vivência condigna. Todavia, não se pode retirar daí que sejam, sem mais, despesas que devem ser comparticipadas nos termos da Lei das AUGI pelos proprietários e comproprietários pois estes, como veremos, apenas terão de proceder à comparticipação das obras de urbanização que forem internas e em regra preexistentes às operações de reconversão e não daquelas que são e seriam sempre infra-estruturas gerais, isto é infra-estruturas que servem os aglomerados como um todo e os ligam às demais partes da urbe.

Não pode ser a Administração conjunta a decidir realizar e custear, sem mais, tais obras de urbanização, independentemente do momento em que as mesmas ocorram e da natureza que as mesmas revistam. Caso contrário, não haveria qualquer limite cogitável à exigibilidade de comparticipações pois não há, segundo parece da argumentação do Tribunal da Relação de Lisboa, qualquer limite à actuação material das Comissões de Administração, a partir do momento em que são legalmente constituídas, e que se passam a comportar factualmente como agentes privados no local, perante a impassividade ou conivência das entidades públicas ${ }^{15}$.

15 O Tribunal refere-se ao Ac. do STA, de 23-09-2003, P. 01606/02, entendendo que o mesmo tem a ver com os deveres que surgem após a aprovação de um loteamento ou plano de pormenor de reconversão "não com aqueles que levam até esse momento e que surgem necessariamente antes", não dando uma resposta cabal quanto aos critérios aplicáveis neste momento intervalar que, assinale-se, dura, pelo menos depois da constituição da presente Administração conjunta, há mais de 16 anos. Ora, a nosso ver, se até poderia fazer sentido num momento inicial ter alguma flexibilidade quanto à execução de algumas obras de urbanização pela Administração conjunta, fruto de algum tratamento das infra-estruturas ilegais preexistentes, já não faz sentido que essa "generosidade" se estenda para além do razoável, sobretudo quando as infra-estruturas em causa passaram, com o reconhecimento das AUGI pelos Municípios, a ser infra-estruturas gerais públicas. De facto, ainda que tais infra-estruturas possam não ser ainda formalmente de titularidade pública, não deixam de servir o acesso público e do público de e para as AUGI, pelo que se integraram já, por força da Constituição e da Lei no domínio público municipal. 
Esta posição amplíssima sobre as possibilidades de intervenção das Administrações conjuntas e sobre as correspondentes responsabilidades dos seus membros é tanto mais perigosa quanto os Tribunais já foram ao ponto de considerar que os aparelhos de ar condicionado e de fornecimento e montagem de equipamento de cozinha, lavandaria e cafetaria de um polo cívico entram nas competências da Administração conjunta e na responsabilidade dos comproprietários. A sentença do Tribunal Judicial da Comarca de Lisboa Norte, de 9-01-2018, P.o 3085/14.9TCLRS, apesar de entender que estas «não são obviamente despesas de reconversão urbanística», estriba-se no Acórdão do Tribunal da Relação de Lisboa, de 9-11-2017, P. 3844/13.=TCLRS.L1-6, para considerar que não são alheias aos fins da AUGI, podendo assim esta decidir atribuir as liberalidades que tiverem sido deliberadas.

Assinale-se, porém, que este acórdão (da Rel. Lisboa, de 9-11-2017) foi, e bem, revogada pelo Supremo Tribunal de Justiça (Ac. STJ, de 27-10-2018, P. ${ }^{\circ} 3844 / 13.0$ TCLRS.L1.S1), pelo que a analogia com o regime jurídico das associações criadas voluntariamente não procede, não podendo a AUGI fazer liberalidade, pois não tem o exercício de um poder de disposição conveniente à prossecução dos seus fins, já que foi criada para cumprir uma finalidade pública e legal especifica.

De facto, no seu acórdão de 27 de Outubro de 2018, o Supremo Tribunal de Justiça concluiu que a Administração conjunta não goza de personalidade jurídica, não dispondo de património autónomo e independente dos seus membros, mas sim de bens próprios dos membros e de natureza comum (contitularidade ou condomínio), pelo que qualquer liberalidade dependeria das regras gerais de aprovação/assentimento de todos os membros da AUGI para poder ser efectivada $\left(1404 .^{\circ}\right.$, n. ${ }^{\circ} 1$ Código Civil).

Regressando ao Acórdão em comentário, entende-se que independentemente da modalidade de reconversão adoptada, a Lei não estabelece qualquer distinção quanto ao pagamento das comparticipações no processo respectivo (artigo 3. ${ }^{\circ}, 1,3$ e 4), bastando que esteja constituída uma comissão da administração e que na mesma sejam admitidos a intervir todos os comproprietários, assistindo-lhes o direito de influenciarem as deliberações tomadas e de as impugnarem judicialmente. 
Acrescenta que "alude-se na letra da lei, genericamente, a "comparticipações” - nas despesas de reconversão - “designadamente”, para as despesas de funcionamento" da comissão de administração, "para execução dos projectos, acompanhamento técnico do processo e execução de obras de urbanização (cf. Art. 15/1-c), não se estabelecendo, portanto, uma ligação com a modalidade de reconversão fixada nem com o título de reconversão aprovado".

É notório desta decisão judicial que o único momento relevante para o Tribunal é o da legal constituição dos órgãos de administração da AUGI, que gera ipso facto um dever de comparticipação que não conhece limites nem regras, sendo irrelevante a modalidade de reconversão e do título que eventualmente venha a ser aprovado, bem como o tipo e natureza das comparticipações aprovadas.

Aquele acórdão considera, textualmente, que o dever de legalização é dos proprietários e comproprietários e que eles têm de proceder sempre ao pagamento das comparticipações, independentemente da modalidade de reconversão selecionada, bastando a válida constituição da Administração da AUGI. É certo que reconhece - como nos parece óbvio - aos interessados o direito de influenciarem as deliberações tomadas e as impugnarem, mas se os motivos para o efeito não procedem nunca - porque a Administração conjunta foi legalmente constituída, único argumento de contestação que seria legítimo à luz do juízo judicial -, então as garantias dos proprietários e comproprietários são irreais, porque estes deixam de, na prática, poder contestar a validade, eficácia e exequibilidade das deliberações tomadas que fixam as comparticipações.

Também quanto aos critérios para definição das comparticipações, o Tribunal, lendo a referência a lotes como "parcelas de terreno, afectas exclusivamente, em termos físicos, aos respectivos comproprietários com exclusão, portanto, dos restantes, e apesar da situação registral reportada a avos", entende que "a assembleia da AC parece ser "soberana" na falta de norma imperativa expressa aplicável”.

Ou seja, nesta visão judicial, não só a Administração conjunta da AUGI pode deliberar sobre quaisquer projectos ou obras, desde que esteja legalmente constituída, independentemente de estas tenderem para a regularização 
urbanística e fundiária da AUGI, como essas obras devem, sem excepção, ser objecto dos devidos adiantamentos e comparticipações, como ainda as regras para o efeito são as deliberadas soberanamente pela Assembleia de comproprietários.

Cumpre questionar, afinal, quais os limites à intervenção da Administração conjunta. Todo o arrazoado judicial a que nos reportamos parece contrariar o facto de a Lei das AUGI ser um regime excepcional e transitório que deve ser lido restritivamente e dentro da função jurídico-pública que desempenha. Do mesmo passo, uma interpretação como a proposta pelo Tribunal da Relação de Lisboa permite e promove uma diluição entre as competências municipais em matéria de regularização fundiária e urbanística e as competências viabilizadoras da Administração conjunta.

De novo, o juízo sobre a natureza necessariamente pública das infra-estruturas em apreço é aqui claro. Mas deveria ser igualmente evidente que, por se tratar de infra-estruturas gerais, as mesmas não deveriam ficar na iniciativa e na responsabilidade da Administração conjunta da AUGI. Tal como em outras áreas da urbe, e como expressamente se encontra reconhecido no regime das AUGI, o Município tem formas financeiras e jurídicas (como a expropriação) para agir nestes casos em que necessita de áreas para imediato uso público, não fazendo depender a sua aquisição de mecanismos de regularização que não se encontram predispostos para o efeito. Se não usa os meios próprios e adequados para fazer face a estas necessidades, contando com o apoio de entidades (AUGI) que apenas deveriam agir tendo em vista a regularização fundiária e não a sua gestão diária, o Município encontra-se a renunciar às suas responsabilidades e competências, uma vez que coloca na mão de privados funções de interesse público que aqueles não estão aptos a desempenhar. De facto, o juízo municipal não deve assentar apenas na ausência ou não de financiamento próprio, sendo que manifestamente não deveria recorrer à AUGI como fonte de financiamento nas situações em que esta entidade é incompetente em razão da matéria para deliberar sobre a execução de infra-estruturas ou assumir outras despesas que excedem a sua restrita vocação legal.

Ora, perante a incapacidade ou passividade dos Municípios em agir de forma consequente nesta matéria, um entendimento deturpado das 
competências legais das Administrações conjuntas conduz irremediavelmente a uma ascensão dos actores privados (das Comissões de Administração, sobretudo), que passam a comportar-se como verdadeiros actores jurídico-públicos, competindo com os Municípios e com as Freguesias, tendo por vezes bastante mais disponibilidades financeiras e operativas do que estas.

Portanto, de uma gestão excecional e transitória, passa-se para uma gestão normal da AUGI, que não tem um fim à vista, e que se encontra manifestamente fora do âmbito do regime legal em apreço, gerando espaços de conflito indesejáveis e evitáveis entre entidades públicas e privadas.

\section{Notas CONCLUSIVAS}

Como referem Margarida Pereira e Filipa Ramalhete, "a constituição das $\mathrm{CaC}$ [Comissões de Administração] criou interlocutores com poder financeiro (quotizações anuais para financiar a reconversão), capacidade para definir uma agenda própria e interferir no processo de decisão (equipa técnica). Estes requisitos impostos por lei às $\mathrm{CaC}$ conferem-lhe um poder efetivo de contra-argumentação das propostas da autarquia, potenciando discordâncias sobre a solução e o modus operandi que, com frequência, se convertem em conflitos intratáveis" ${ }^{16}$. Ou então, acrescentamos nós, poder-se-ão criar situações, como a verificada no caso objeto de decisão judicial, de aliança entre os Municípios e as Comissões de Administração no sentido de manter inalterado o status quo.

Situações destas tendem a perpetuar as Assembleias de comproprietários e as Comissões de Administração, uma vez que, podendo estas fazer tudo o que entendam sem título de reconversão, como se a situação das AUGI fosse legal, deixa de se ter de insistir na aprovação deste título que, assim, ficará para quando for inevitável a sua aprovação pelos órgãos municipais.

Com os efeitos laterais da (des)mobilização dos (com)proprietários, que deixam de acreditar na condução do processo de regularização e nos moldes

16 "Planeamento e conflitos territoriais: uma leitura na ótica da (in)justiça espacial", Finisterra n. ${ }^{\circ}$ 104 (Abril, 2017): 20. 
como os mesmos são levados a cabo ${ }^{17}$, e da desresponsabilização dos poderes públicos quanto a deveres que lhe são cometidos por lei.

Julgamos que o Acórdão em comentário, ao ter partido de um pressuposto de que basta a constituição de uma Administração Conjunta para esta poder ter poderes amplos, que rivalizam, mesmo, com os dos poderes públicos, não contribui para a clarificação da questão de saber quais as comparticipações que, afinal, são exigíveis aos proprietários e comproprietários de uma AUGI. E é, afinal, mais um argumento no sentido da inexigibilidade em concreto da reconversão das AUGI.

De facto, se a gestão de uma AUGI é feita, na prática, tal como se esta fosse plenamente legal, de que interessa ao Município e às comissões de administração das AUGI insistir na tarefa tortuosa da sua regularização urbanística e fundiária?

17 Isabel Raposo e Ana Valente, "Diálogo social ou dever de reconversão..., cit., p. 231. 
